\title{
A new scheme for the electro-hydraulic servo system control of electrodes in an electric arc furnace
}

\author{
Wang Gang \\ Cao Xinming \\ Zhou Shichang \\ Lecturer \\ Professor \\ Professor \\ Dept. of Mech. Elec. Eng. \\ Dept. of Mech. Eng. \\ Shenyang Institute of Gold Tech. \\ Northeast University of $\mathrm{T} e c h$.
}

Shenyang, Liaoning, P. R. China

\begin{abstract}
This paper proposes a new control scheme for the electrode servo control system in an electricarc furnace. The cylinder is controlled by a servo valve along with two on-off control valves. The optimal opening and closing time of the on-off valves is determined by the principle of optimality. This can protect the zero velocity and acceleration at the stopping point of the cylinder as well as the minimum response time. By this kind of control, the servo valve gives the fast response and high position accuracy under small disturbance and the on-off valve control provides fast response and small impact following a large disturbace. Experiment and digital simulation are carried out for a step input, the two results are similar.
\end{abstract}

\section{KEYWORDS}

hydraulic, control, electric-arc furnace, optimal

NOMENCLATURE

$\mathrm{B}=$ damping coefficient of the cylinder

$\mathrm{Fe}=$ force load of the cylinder $\mathrm{g}=\mathrm{gravitational}$ acceleration

$\mathrm{H}=\operatorname{arc}$ length

$\mathrm{K} p=$ proportional coefficient of the PI regulator

$\mathrm{L}=$ height of steel level

$M=$ mass of the moving part of cylinder

Ps $=$ oil source pressure

Fluid Power. Edited by T. Maeda. (C) 1993 E \& FN Spon. ISBN 0419191003. 
$\mathrm{t}_{0}=$ initial time of the transient

$\mathrm{Tr}=$ integral time constant of the PI regulator

$\mathrm{U}=$ control signal

$\mathrm{U}_{+}=$control signal when cylinder pressure equals Ps

$\mathrm{U}_{-}=$control signal when cylinder pressure equals 0

$\mathrm{Xp}=$ displacement of cylinder

$\mathrm{Y}=$ height of electrode end

\section{INTRODUCTION}

The electrode control of modern electric-arc furnaces is mostly done by a hydraulic servo control[1]. Because disturbances in the electric-arc furnace are largely different in form and magnitude from each other, the electrode control system should have high positional accuracy for small disturbance as well as fast response for large disturbance. One method for this purpose is to use the servo valve with varying gain $[2]$. However, it then exhibits significant overshoot, its nominal flow should be large enough to satisfy the highest velocity of cylinder.

We suggest a new control scheme which uses a small servo valve along with two large onoff valves to control the electrode hydraulic cylinder. The servo valve is used for small disturbances and the on-off valves for the large disturbances. The optimal opening and closing time of the on-off control valves are determined by the method of optimality to produce the least overshoot under the prerequisite of fast response.

Past studies on the electrode servo control system mostly were carried out for open loop case, the electric-arc is not included in the loop because of the difficulty of measuring the arc length $[3][4]$. In order to study the performance of the electrode control system in more detail, we established an experimental electric-arc furnace and measured the characteristics of the whold system including the electric arc. The management of control style (servo valve control or on-off control), the PI regulation and digital filtration of the sampling data are realized by a microprocessor.

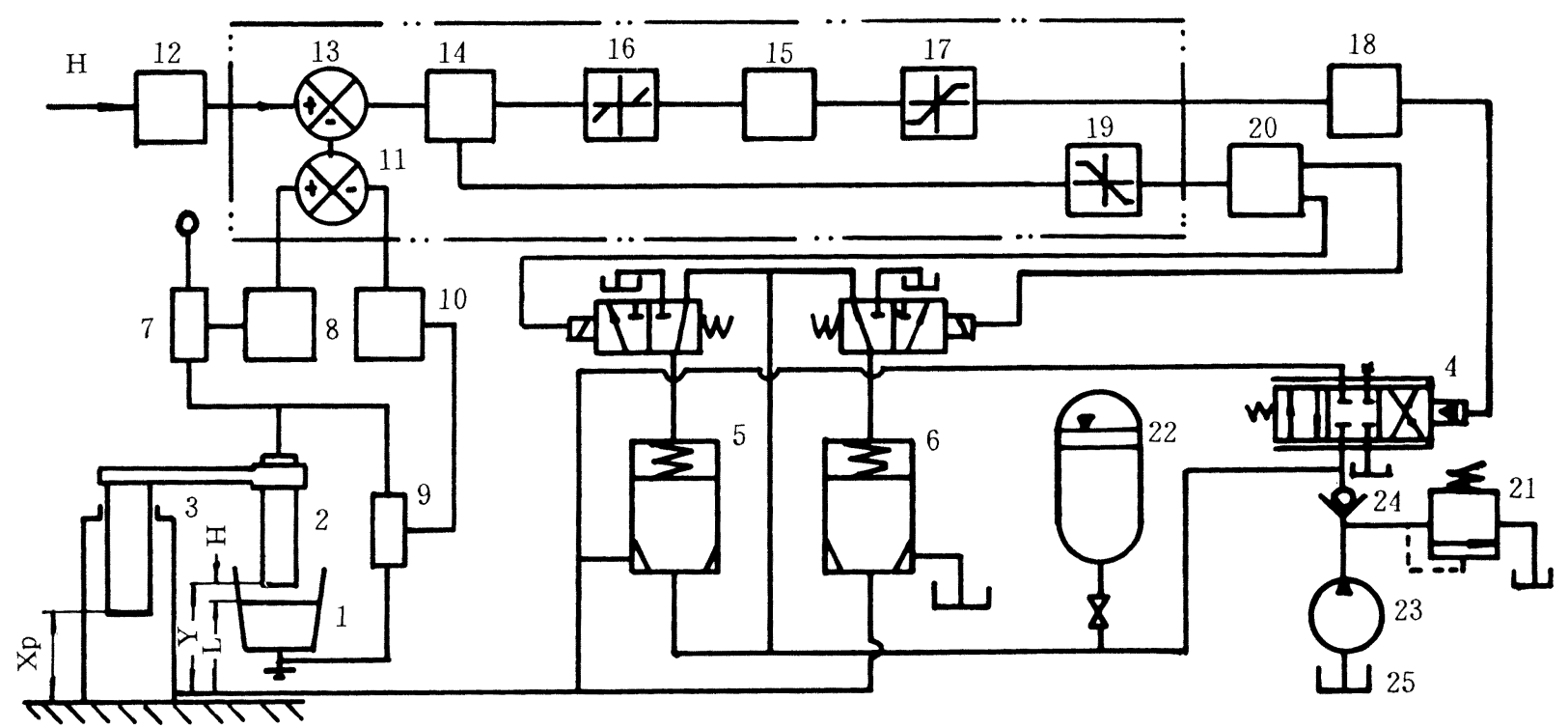

Fig. 1 Scheme of the electrode control system 


\section{SCHEME OF THE ELECTRODE CONTROL SYSTEM}

Fig. 1 shows the scheme of one phase of the 3 -phase electrode control system.

The electrode 2 is driven up and down by the cylinder 3 . The input value $\mathrm{H}$ of the electric arc length is given by the microprocessor according to the technological requirements and is input into the amplifier 12. The actual electric current and voltage through the electric arc are measured by current and voltage transformers 7 and 9 and then through amplifiers 8 and 10 are compared in the comparator 11. The difference reflects the actual arc length. In error detector 13, the actual arc length and the input arc length $\mathrm{H}$ are compared with each other and the error is input into the supervision unit 14 in the microprocessor.

When the error is comparatively small, it will be sent into the power-amplifier 18 through PI regulator 15 and transformed into a current signal to control the servo valve. Then the servo valve controls the cylinder 3 up and down to reduce the error to zero. In the microprocessor, a dead band unit 16 is set in to prevent the electrode vibration caused by the small signal variation. The ampliude limiting unit 17 is used to prevent any very high signal potentially harmful to the servo valve.

When the error signal is comparatively large, the supervision unit 14 will start the optimal on-off control circuit 20 according to the onoff control curve 19. Then the cartridge valves 5 and 6 will control the cylinder to move to the required position.

Pump 23, relief valve 1 , accumulator 2 and check valve 24 compose the constant pressure oil source of the system.

\section{SERVO VALVE CONTROL UNDER SMALL PERTURBATION}

When the system is under small perturbation, the servo valve willoperate. The block diagram of such a value controlled cylinder system is shown in Fig. 2. The transfer function block diagram of the whole system can be obtained as Fig. 3 .

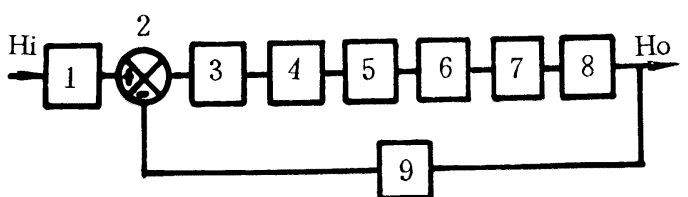

Fig. 2 Block diagram of servo valve controlled cylinder system

1 displacement transformer 6 amplifier

2 error detector 7 servo valve

3 dead band 8 cylinder

4 PI regulator 9 displacement

5 amplitude limiting

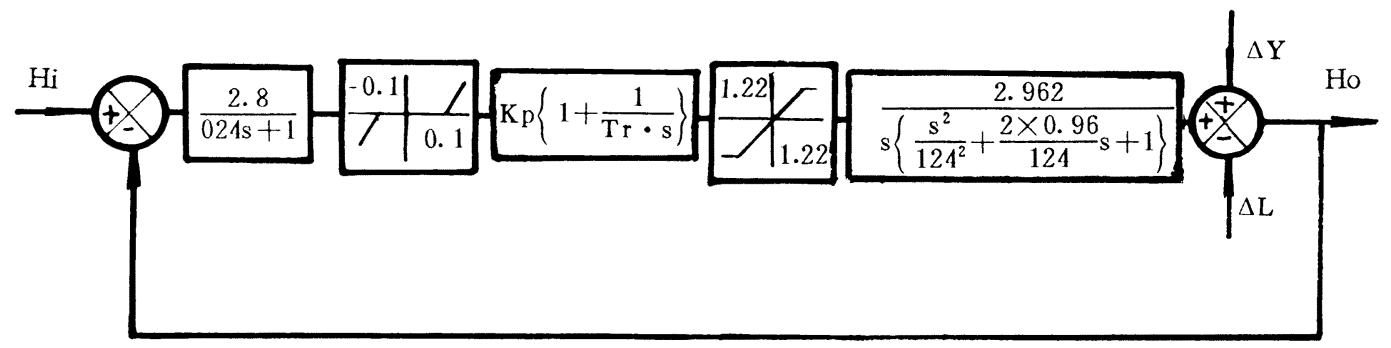

Fig. 3 Transfer function block diagram of the electrode control system 
OPTIMAL TIME OF ON-OFF VALVE CONTROL UNDER LARGE DISTURBANCE

In the case of a large disturbance, the cylinder is controlled by two on-off valves (cartridge valves) as shown in Fig. 4.

When the cylinder was controlled only by one valve, it would oscillate near the stopping point due to the effect of load inertia and oil elasticity. This would mean that the velocity would not equal to zero when the cylinder reached its stopping position, If two valves (valves 3 and 4 in Fig. 4) are used and their opening and closing times are correctly selected by the method of optimality, the velocity and acceleration can be kept equal to zero at the stopping point. Therefore the impact can be avoided. For example, when the cylinder is needed to ascend, the valve 3 is opened and cylinder goes upward. At a rational time before the cylinder reaches its stopping point, the valve 3 is closed and valve 4 is

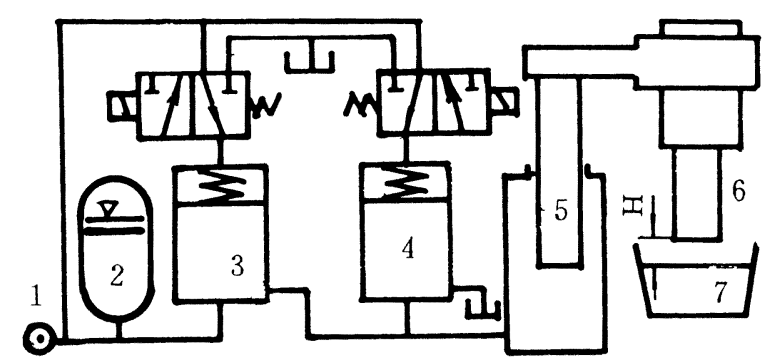

Fig. 4 Optimal time control system by on-off valves

$\begin{array}{ll}\text { 1-oil source, } & \text { 5-cylinder, } \\ \text { 2-accumulator, } & \text { 6-electrode, } \\ \text { 3. 4-cartridge valve, } & \text { 7-steel level. }\end{array}$

opened, so the pressure in the cylinder is dropped and the cylinder will decrease its as- cending velocity. When the cylinder reaches its stopping point, its velocity and acceleration will precisely decrease to zero. Therefore the cylinder will stop exactly at the required position and no oscillation will occur. At that moment, valve 4 is closed.

The closing time of valve 3 and opening time of valve 4 is determined by the method of optimality, so we have to set up the state equations of the system.

When the cylinder moves upward, the pressure in the cylinder equals to the source pressure Ps. The dynamic equation will be

$$
\mathrm{Ps} \cdot \mathrm{A}=\mathrm{M} \ddot{\mathrm{X}} \mathrm{p}+\mathrm{BX} \mathrm{p}+\mathrm{Fe}+\mathrm{Mg}[1]
$$

When the cylinder moves downward, the cylinder pressure equals to zero and $\mathrm{Xp}$ changes its sing, so

$$
\mathrm{Mg}=\mathrm{M} \ddot{\mathrm{X}} \mathrm{p}+\mathrm{B} \dot{\mathrm{X}} \mathrm{p}+\mathrm{Fe}
$$

Let

$$
\begin{gathered}
\mathrm{U}_{+}=(\mathrm{APs}-\mathrm{Mg}-\mathrm{Fe}) / \mathrm{M} \\
\mathrm{U}_{-}=(\mathrm{Mg}-\mathrm{Fe}) / \mathrm{M} \\
\mathrm{a}=\mathrm{B} / \mathrm{M}
\end{gathered}
$$

Eqs. $[1]$ and $[2]$ can be replaced by Eq.

$$
\ddot{\mathrm{X}} \mathrm{p}+\mathrm{aX} p=U
$$

Where

$$
\begin{gathered}
\mathrm{U}= \begin{cases}\mathrm{U}_{+} & \text {cylinder pressure equals } \mathrm{Ps} \\
\mathrm{U}_{-} & \text {cylinder pressure equals } 0\end{cases} \\
\text { Let } \quad \mathrm{X}_{1}=\mathrm{Xp}, \mathrm{X}_{2}=\dot{\mathrm{X} p}
\end{gathered}
$$

The state equations can be obtained from Eq. $[6]$ as

$$
\begin{aligned}
& \dot{\mathrm{X}}_{1}=\mathrm{X}_{2} \\
& \dot{\mathrm{X}}_{2}=-\mathrm{aX}_{2}+\mathrm{U}
\end{aligned}
$$

Treat the $U$ as the control signal, the $U$ satisfies the following restriction:

$$
\mathrm{U} \leqslant \mathrm{U} \leqslant \mathrm{U}_{+}
$$

The initial and terminal conditions are that 
the velocity and acceleration equal zero. The condition that the time reaching the terminal condition is minimum is used as the performance index. By the Pontryagin's maximum principle [5], we can solve the state equations and obtain

$$
\mathrm{X}_{1}=-\frac{\mathrm{U}_{+}}{\mathrm{a}^{2}} \ln \frac{\mathrm{U}_{+}-\mathrm{a} X_{2}}{\mathrm{U}_{+}}+\xi-\frac{\mathrm{X}_{2}}{\mathrm{a}}
$$

for

$$
\mathbf{U}=\mathbf{U}_{+}
$$

Where

$$
\xi=X_{1}\left(t_{0}\right) \leqslant 0
$$

$$
X_{1}=-\frac{U_{-}}{a^{2}} \ln \frac{U_{-}-\mathrm{ax}_{2}}{U_{-}}+\xi^{\prime}-\frac{X 2}{a}
$$

for

$$
\mathrm{U}=\mathrm{U}_{-}
$$

Where

$$
\xi^{\prime}=X_{1}\left(t_{0}\right) \geqslant 0
$$

The curves in Fig. 5 represent Eq. [9] and $[10]$. These curves can be used to choose the optimal opening and closing time of the onoff valves.

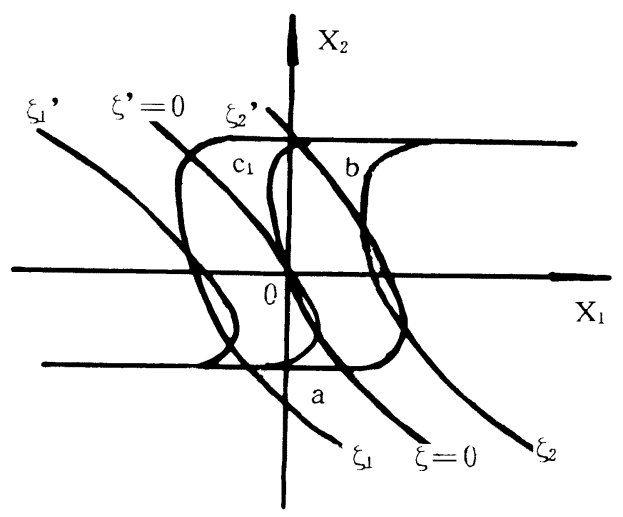

Fig. 5 Optimal control trajectory

In Fig. 5 the abscissa represents the velocity and the ordinate represents the acceleration. Therefore, only at the origin 0 the velocityand accelerationare equal to zero. Only the trajectory for $\xi=0$ passes through the origin. If we want the velocity and acceleration at the stopping point equal to zero, we must guide the control to approach the $\xi=0$ curve. For example, if the cylinder ascends, it means $\xi<0$, suppose $\xi=\xi_{1}$, the control of the system will vary according to the curve a in Fig. 5. When the control reaches the point $c$, curve a conincides with the $\xi=0$ curve. At that moment, the control signal opens valve 3 and closes valve 4 in Fig. 4. This means $U$ $=\mathrm{U}_{-}$-and the control trajectory will vary according to the $\xi=0$ curve to orig in 0 in Fig. 5 and the cylinder stops with zero end velocity and acceleration. If the cylinder descends at first, that means $\xi^{\prime}>0$, suppose $\xi^{\prime}=\xi_{2}^{\prime}$, the control will vary according to the curve $b$. When it reaches $c$ and coincides with $\xi^{\prime}=0$ curve, the control singnal opens valve 3 and closes valve 4 , this means $\mathrm{U}=\mathrm{U}_{+}$and the control will vary according to the cvrve of $\xi^{\prime}$ $=0$ to the origin in Fig. 5. This kind of control can keep the cylinder to reach the required position in the shortest time with zero terminal velocity and acceleration.

\section{MICROPROCESSOR CONTROL}

In this control system, many functions are realized by microprocessor e.g. the setting of the input vlaue of $\mathrm{H}$, the comparison of input and actual values of $\mathrm{H}$, to form the dead band and saturation, PI regulation and supervisory functions. The frequency of scanning on the samplig values of arc current and arc voltage is $100 \mathrm{~Hz}$ and the digital filter is used to decrease the disturbance of noise to the lowest level. We use the synchro regulation method to avoid the accumulation of sampling error induced by the frequency fluctuation of actual arc current and voltage.

\section{EXPERIMENT AND COMPUTER SIMULATION}

A digital computer was used to simulate the 
response of the electrode system controlled by a servo valve along with two on -off valves with respect to a $10 \mathrm{~mm}$ step input of $\mathrm{H}$, the simulated result is shown as the dashed line in Fig. 6. We also carried out an experimental result which is shown as the solid line in Fig. 6. The two curves are similar.

We also compared the digital simulation of these two kinds of control at the same nominal flow rate. The response time of servovalve control system to a $10 \mathrm{~mm}$ step input is 0 . $3 \mathrm{~s}$ and the response time of optimal time

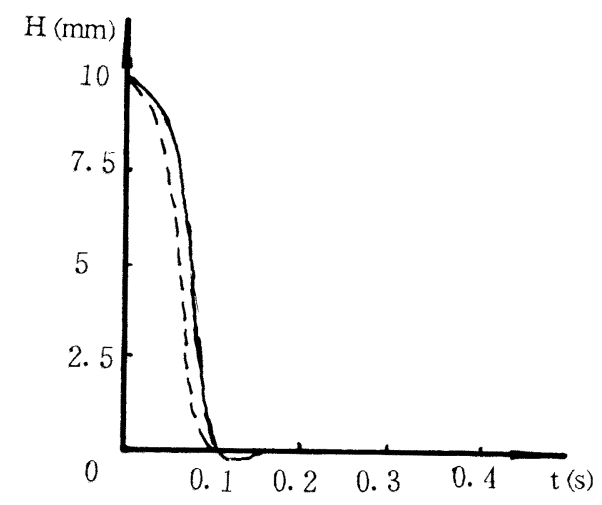

Fig. 6 Experimental and simulation results of step response

on-off valve control system is $0.2 \mathrm{~s}$. This exhibits the advantage of using a servo valve along with two on-off valves to control the electrode control system.

\section{CONCLUSION}

1. By using a servo valve plus on-off valves to control the electrode control system the advantages of fast response and high position accuracy for small disturbance can be achieved as well as fast response and small impact for large disturbance.

2. The optimal opening and closing time determined by the method of optimality can protect zero velocity and acceleration at the stopping point of cylinder and therefore the impact is small and the move is smooth.

\section{REFERENCES}

[1]Guo Maoxiang" Handbook of Metallurgicala Electric Regulation"Metallurgy Press (Chinese), 1975

[2]Ro Zhizhing" Servo Valve With Varying Gain" 1st Conference on Fliud Power in Metallurgy, Chendu, 1980

[3] Cao Xinming etc." The Identification of Hydraulic Servo Control System of Electrode of an Electric-arc Furnace", Proc. of the 2nd CCEA, Sydney Australia, 1986

[4]Zhou Shichang etc. "Mathematical Model and Numerical Simulation of the $\mathrm{Hy}-$ draulic Servo Control System of a Vacuum Electric-arc Furnace", Proc. of 1987 ACC, Minneapolis USA

[5]Bryson A. E. and Ho Y. C. "Applied Optimal Control" Blaisdell Publishing Co. , Lexington, Massachusetts, 1969 